\title{
NIETZSCHE: LA EXPERIENCIA DIONISÍACA DEL MUNDO. UN COMENTARIO
}

\author{
Ignacio CaSTILLO Franco
}

Estamos enfermos, enfermos de nihilismo. A este diagnóstico que Nietzsche hizo de nosotros, los europeos de su tiempo y los de hoy (todos los que venimos de la Ilustración y de más allá, de Cristo y de Sócrates y Platón) dedica Diego Sánchez Meca su último libro Nietzsche. La experiencia dionisíaca del mundo ${ }^{1}$. El libro se estructura en tres partes bien diferenciadas. En la primera de ellas se da cuenta de cómo el filósofo alemán se hizo con la herramienta que le permitiría emitir el mencionado diagnóstico, el método genealógico según el cual toda institución cultural, sea religiosa, moral, política, artística o filosófica, es el producto de atávicos juicios de valor (qué es bueno y qué es malo) que el hombre introyectó e incorporó en forma de instintos que reflejan así las condiciones de existencia necesarias para aquel que los emitió. Nuestros valores representan en realidad nuestras condiciones de vida. Todo producto supuestamente ideal, cultural, espiritual debe ser pues remitido a un estrato más profundo del que proviene, el cuerpo, que es ciertamente el que valora, el que, por medios no conscientes, plasma en una determinada configuración de instintos las condiciones que favorecen su vida. Hay así una relación muy estrecha entre la cultura y el cuerpo (podría aquí hacerse una grosera comparación con el método marxista que consiste en dirigirse a las condiciones materiales o infraestructura siempre que se quiera saber el origen de una manifestación concreta en el nivel de la superestructura). A través de dicha relación se puede determinar si una cultura ha sido producida por un cuerpo sano, caracterizado por la sobreabundancia de fuerza física, la vitalidad, el amor a lo sensible, etc., o por el contrario proviene de un cuerpo enfermo, débil, decadente, que desprecia los estados de sobreabundancia de fuerza física, la exuberancia, los impulsos vitales y todo lo sensi-

1 Sánchez Meca, D., Nietzsche: La experiencia dionisiaca del mundo, Madrid, Tecnos, 2005. 
ble. De las condiciones de vida para un cuerpo sano, que haga unas valoraciones sanas, se derivarán ciertos impulsos así como una cultura afirmativa, mientras que de las de un cuerpo enfermo, que hará necesariamente otras valoraciones, surgirá una configuración instintual distinta en el individuo y una cultura nihilista Este último caso es el nuestro, el de la cultura europea que nació de la condena y miedo que ciertos hombres sentían hacia esos estados de sobreabundancia de poder, de vitalidad exuberante, valorizando los estados opuestos de debilitamiento, represión de los instintos más vitales, la culpa, la negación del yo, etc. Y por eso el europeo de hoy que se cree la cima de la evolución, que ha subyugado a la naturaleza y la ha sometido para ponerla a su servicio, no se siente satisfecho y feliz ( $\mathrm{y}$ ese use siente» denota ya que ese malestar proviene de un estrato tan profundo como el cuerpo).

En la segunda parte del libro se analizan algunos de los síntomas de ese nihilismo, es decir, cómo se manifiesta en algunos de los ámbitos culturales (en el lenguaje, en la política,...) y se estudia la terapia propuesta por Nietzsche para erradicar esta enfermedad: la transvaloración que sustituya la nihilista cultura europea por una cultura con unos valores afirmativos que han de ser el reflejo de una nueva configuración instintual del hombre, de un nuevo hombre, un superhombre cuyos valores nazcan de una actitud distinta y afirmativa ante la vida, de un cuerpo sano.

En la tercera y última parte Sánchez Meca repasa tres interpretaciones del pensamiento nietzscheano, las de Habermas, Heidegger y Deleuze y las compara con la suya propia.

\section{1. ${ }^{\text {a }}$ parte. "La victoria sobre el dolor. El ejemplo de la serenidad griega»}

La tesis que defiende Sánchez Meca es que fue en su juventud, al hilo de su examen sobre el arte, la tragedia griega y la música wagneriana, cuando Nietzsche fue pergeñando su genealogía para, posteriormente, extender esta clase de análisis inicialmente circunscrito al arte aplicándolo a cualquier esfera de la cultura.

El joven Nietzsche, el de El nacimiento de la tragedia en el espiritu de la música, se hallaba aún prisionero del paradigma romántico de sus admirados Scho- 
penhauer y Wagner, paradigma que podría caracterizarse por la tesis central que el primero habiá expresado en El mundo como Voluntad y representación ${ }^{2}$. Allí Schopenhauer (muy influido por la religión hinduista y su especulación de las Upanishad, con el «tat vam asi» o "eso eres tún, la ecuación que iguala el individuo o atman con el cosmos o Brahma) expresaba el desgarro originario del ser o mundo cuya esencia última, la Voluntad, necesita expresarse u objetivarse mediante el despliegue de una multitud de fenómenos engendrados por su querer vivir. Ese ámbito apolíneo de la apariencia transitoria y momentanea, de lo individual, de la representación, es al que pertenecemos, pero a su vez late en nosotros como voluntad, como querer vivir, aquella unidad originaria de la que surgimos. El místico deseo de vuelta al origen, de disolución en el todo amorfo e indiferenciado, se conseguiría a través de la música, el único arte dionisíaco porque habla directamente el lenguaje de la Voluntad (no como otras artes apolíneas, la escultura por ejemplo, que son una mediación ya que representan la representación), expresa directamente el devenir, ese crearse y destruirse de todas las formas individuales movidas por su afán de vivir. A su vez Wagner, con una serie de recursos propios como son la emancipación de la melodía con respecto a la armonía (cuya subordinación era uno de los axiomas de la ortodoxia musical), la melodía continua o leitmotiv que generaba una inmensa frase sinfónica, la división en compases irregulares, etc., habría querido representar con su música aquella concepción que Schopenhauer expresara con palabras (en unas páginas muy didácticas Sánchez Meca nos hace entender a los que no sabemos nada de música cómo conseguía Wagner tales efectos). Es decir, entonces, en 1872, año de publicación de El nacimiento de la tragedia, la música wagneriana, junto con la de la tragedia griega, eran las únicas músicas dionisłacas porque expresaban la esencia o en sí del mundo como Voluntad, ese querer vivir que constituye cada fenómeno que aparece en la esfera de lo apolíneo y que es el ligamen de todos ellos en ese continuo devenir, a la vez que aquello en lo que finalmente deben

2 Recuerdo como narraba Nietzsche en los escritos póstumos su encuentro, allá por la época melancólica de sus veinte años, con este libro: "Creo que no será difícil imaginar la impresión que, en esta situación, tenía por fuerza que causarme la lectura de la obra principal de Schopenhauer. Encontré un día este libro en la librería de viejo del anciano Rohm. Ignorándolo todo sobre él, lo tomé en mis manos y me puse a ojearlo. No sé que demonio me susurró "llévate este libro a casa». Ocurrió, en cualquier caso, contra mi usual costumbre de no precipitarme en la compra de libros. Una vez en casa me arrojé con el tesoro recién adquirido a un ángulo del sofá y comencé a dejar que aquel genio enérgico y sombrío influyera sobre mín. En la edición de las Nietzsche Werke de K. Schlechta, Carl Hauser Verlag, München, 1954, tomo III, p. 133. 
diluirse otra vez, retornando a su origen. Pero el joven Nietzsche que aún se desgarraba él mismo por la adhesión a sus maestros y las poderosas intuiciones que les acusaban como pesimistas decadentes, iría abandonando a lo largo de la década de 1870 ese paradigma romántico a medida que fue dando forma a aquellas intuiciones y adquiriendo una nueva comprensión de lo que supuso el mundo griego, su tragedia, la música y el arte en general, así como un concepto distinto de lo que era lo dionisiaco. En ello habría tenido mucho que ver la concepción nietzscheana del lenguaje como algo convencional, algo creado como herramienta eficaz para el dominio del mundo, para la vida, algo pues que pertenece necesariamente a la esfera de apolíneo, un fenómeno más, pura apariencia, algo que sólo se representa a sí mismo. La música ya no podía ser pues ese lenguaje natural, directamente significativo, que expresaba la esencia del mundo, es más, ni siquiera existía ningún misterio metafísico como esa supuesta Voluntad o esencia del mundo, no existía ningún en sí, ningún trasmundo, sino solamente el mundo de la apariencia. La música ya no revela la Voluntad del mundo sino sólo al que la hace, la estética está ligada a condiciones biológicas y hay que descubrir al artista detrás de la obra de arte, las fuerzas vitales que la crearon. Esta tesis explica perfectamente la "repentina" ruptura de Nietzsche con el maestro de Bayreuth, pues alguien que concibiese la música como él sólo podía ser un nihilista, alguien que aspira a disolverse en la nada, alguien que lo único que afirma es el caos primigenio y que por ello se ve compelido a hacer una música caótica. Porque para Nietzsche ahora la experiencia dionisiaca del mundo va a consistir en afirmar la vida tal cual es, en afirmar que la vida, el mundo, no es más que ese inmenso caos que percibimos, el cual no es distinto de lo que nosotros somos, y sin postular un mundo más allá, auténtica y esencialmente verdadero. Para expresar esa visión del mundo Nietzsche utiliza el concepto de «voluntad de poder"; que el mundo es voluntad de poder significa que es confrontación continua de fuerzas que luchan por dominarse las unas a las otras imponiéndose su interpretación, dándoles a las dominadas un sentido, unificándolas bajo una forma. Lo dionisíaco no es dejarse disolver o disgregar por ese inmenso caos que es el mundo y que uno es, sino dominarlo, interpretarlo, darle sentido, someterlo a forma o ley. Eso es lo que hacía excelsamente el arte clásico y lo que se hace en el fondo cuando se crea un lenguaje, cuando se hace ciencia, se imponen categorías, ritmos,..., para hacer posible la vida. Lo que sucede es que hay que preguntar ¿qué clase de vida? Aquella que reniega de lo que ella misma es, pues nosotros también somos un caos de fuerzas, una voluntad de poder, hará una interpretación enferma, tendrá unos valores enfermos y generará todo un len- 
guaje, ciencia, arte,..., cuyas categorías están dirigidas a preservar las condiciones de su vida enferma. Un ejemplo claro es el concepto de "deber ser" que rige la moral europea y que no refleja más que un deseo de corregir la vida, una incapacidad para aceptarla y soportarla tal y como es. Otro ejemplo es la obsesión por calificar como malo el dolor, el sufrimiento. En un mundo que es voluntad de poder el sufrimiento es algo natural, consustancial, se deriva de la oposición que presenta toda fuerza a ser dominada o interpretada por otra y es, por ello, la condición necesaria del placer, sentimiento que acompaña inherentemente a la superación de toda fuerza que presentaba resistencia. Para alguien que experimente el mundo dionisiacamente, que lo afirme y lo vea como voluntad de poder, no puede constituir el sufrimiento un problema, algo que deba ser erradicado a toda costa. Por todo ello no son extraños los reproches "fisiológicos" que el Nietzsche maduro dirigía a la música de Wagner como fruto de la decadencia, de la fatiga, del disgusto por la vida, de alguien que anhela escapar a otro mundo porque éste le hace sufrir. Es también lo mismo que impulsó al cristianismo y a la filosofía desde los tiempos de Platón, la revancha de unos seres débiles contra este mundo que, para calumniarlo y poder juzgarlo, se inventaron un trasmundo (cielo, mundo de las Ideas) en el que no había sufrimiento. Pero esto es sólo la revuelta de un tipo de hombre contra la realidad, los que sufren por la realidad, los que son ellos mismos una realidad fracasada.

A pesar de esta evolución Nietzsche dirá que lo esencial ya estaba allí, en $E l$ nacimiento de la tragedia con aquella concepción del arte como la auténtica actividad metafísica del hombre para abrirse al ser y comprenderlo, el poder de crear ficciones, del mismo modo que lo es todo conocimiento. Lo que habría sucedido es que él se habría visto extraviado por aquellos metafísicos románticos que mentían demasiado (pues algo de mentira, de ficción es inevitable en el crear) pretendiendo alcanzar lo profundo, lo esencial, lo en sí. El verdadero y honesto filósofo es aquél que se sabe un animal obligado a crear ficciones y se acepta así, tal como es. También acepta el mundo tal y como es, como siendo sólo una de esas ficciones, forma o apariencia, sin buscarle un sentido más allá, fuera de él. Por ello dirá Nietzsche que la realidad sólo tiene un sentido estético, porque el arte (y el mundo como voluntad de poder es arte) es un puro juego de formas, de apariencias. La verdad es la apariencia, no un más allá. El arte, ejemplarmente el clásico, consiste en someter un caos de fuerzas e impulsos dándoles una forma, no permitir que se dispersen y disgreguen violenta y anárquicamente, es decir, la actividad artística refleja lo que es el mundo como tal, como voluntad 
de poder, una lucha sin descanso de fuerzas que se interpretan unas a otras, que vencen al dar un sentido a las que quedan sometidas a forma, ley y unidad. En ser consciente de esto consiste la experiencia dionisiaca del mundo, aquella que alcanzaron los griegos con su pesimismo estético, o de la fuerza, que adoraba las apariencias, y no ese pesimismo metafísico que reniega de ellas (Platón o Schopenhauer por ejemplo). El arte es lo antinihilista por excelencia, la más alta afirmación que cabe hacer de la vida.

Con la nihilista cultura europea se inocula a los seres unos impulsos hostiles hacia la vida. Por impotencia y debilidad se niega la vida, sus aspectos trágicos y terribles. Hay en la debilidad un caos pulsional que no puede ser sometido a ley. La moral cristiana promueve el odio a todo aquello que es humano, animal, material, carnal, apariencia, cambio, devenir. Mas la vida es lucha, dominación de unas fuerzas sobre otras, y cualquier moral, al igual que el arte, es útil al que la practica al corresponderse con sus condiciones de existencia, con lo que necesita su cuerpo. Las morales son lenguajes cifrados de estados corporales. Es el cuerpo la fuente de toda valoración e interpretación que, convertidas en instrumento de culturización, vuelven a su vez a actuar sobre los cuerpos, bien fortaleciéndolos o bien debilitándolos. Nietzsche está concibiendo ahora la moral según el esquema que había elaborado en su anterior análisis del arte; ambos brotan del cuerpo y vuelven a influir en él aumentando o disminuyendo su fuerza. Según este esquema el cristianismo, el platonismo, el romanticismo, Schopenhauer $y$ Wagner tienen que ser decadentes, voluntades enfermas con cuerpos fisiológicamente mal constituidos para los que es una necesidad vital reaccionar contra ciertos instintos: «mientras la vida asciende felicidad es igual a instinto»"

\section{2." parte. "Transformar Europa. Un experimento con la verdad»}

El examen de la música de Wagner que hiciera el joven Nietzsche había sido el laboratorio para la posterior crítica de la cultura europea. Si se escrutan genealógicamente los distintos ámbitos de esa cultura, es decir, si se los pone en relación con el cuerpo, con la fuerza o voluntad de poder (pues el cuerpo no "está hecho" de otra cosa que el mundo) que los creó artísticamente (sometiendo la multiplicidad a esquema o unidad) se nos revelará su intrínseco nihilismo, su genealogía, su descendencia de fuerzas reactivas.

\footnotetext{
${ }^{3}$ Crepúsculo de los idolos, El problema de Sócrates, aforismo 11.
} 
El lenguaje, como cualquier otra actividad artística, creó conceptos reduciendo la multiplicidad a unidad, pero les atribuyó el carácter de entidades sustanciales trasmundanas o metafísicas (las Ideas de Platón son paradigmáticas al respecto) y en este pero reside lo condenable. Así se acusaba a los sentidos de mentirosos al mostrar sólo cambio y devenir (hay que recordar el aprecio que sentía Nietzsche por Heráclito, el filósofo del devenir). La voluntad de poder que creó ese lenguaje tenía miedo y resentimiento hacia lo sensible. La "sustancia», el "yo", la "causa», ..., todo son mentiras. La necesidad de comunicación obliga a crear unidades fijas de sentido, pero nada obliga a atribuirles una existencia trasmundana, una realidad esencial y metafísica. El entramado conceptual del lenguaje "europeo" procede de una voluntad que se revuelve contra la enorme multiplicidad del devenir del mundo, de un mundo sensible. La gramática intoxica a los individuos al inocularles la creencia en estas entidades: sujeto, acción,... Impide así el acceso a la experiencia estético-dionisiaca de afirmación del devenir que tuvieran los griegos presocrátricos. Por eso Nietzsche buscó para sí lenguajes alternativos al lenguaje estereotipado de la transmisión de conocimientos, de la gramática metafisica. Así es como utilizaba la música, la poesía,..., lenguajes que pudiesen hablar bien del devenir.

Lo mismo sucede si sometemos a análisis genealógico al Estado moderno de las democracias burguesas que se ha disfrazado con toda una serie de máscaras morales: el bien común, la igualdad de derechos,.... Una vez más este Estado se revela como nacido de un acto creativo de coacción que lo hizo surgir como forma de una comunidad a partir de la pluralidad de individuos, pero fue una creación de fuerzas reactivas. Ese Estado no es más que una herramienta al servicio de intereses económicos (la obsesión por la seguridad y el confort es otra característica de lo débil), un instrumento para producir hombres de rebaño, estandarizados, homogéneos, intercambiables, esclavos que no se atreven a darse sus propias normas. Ese Estado aborta de raíz cualquier posibilidad de aparición de un individuo fuerte, aristócrata, distinto, dionisiaco. Para Nietzsche el Estado debe ser el freno al poder disgregador de los intereses individuales y la herramienta para la creación de una cultura superior a través de la promoción de hombres superiores, pero su absolutización, la del Estado, como pretenden los socialistas, procede también de fuerzas reactivas que persiguen la igualdad para todos, la rebañización. El socialismo es un cristianismo secularizado y al igual que hizo éste con su enemigo el Imperio romano, hace él con el suyo, la democracia burguesa, no intenta destruir el Estado, sino conquistarlo para sí. También el nacio- 
nalismo, otra idolatría del Estado-nación, procede de fuerzas reactivas incapaces de asimilar y digerir la pluralidad cultural. Así pues, estas tres ideologías, liberalismo, socialismo y nacionalismo persiguen la igualación del hombre que anhela toda fuerza reactiva, hostil a la singularidad, a la autonomía, a los fuertes. Y lo persiguen con el Estado como herramienta. Es lo más opuesto a lo que sucedía en la polis griega que fomentaba la lucha leal entre individuos distintos.

Sea cual sea el ámbito de la cultura europea que se examine siempre aparecen allí los rasgos de la debilidad, de la reactividad, y muy especialmente dos de ellos: 1) la valoración negativa de los estados corporales de fuerza excesiva (que hay que debilitar convenientemente) y que se traduce en esa característica aristofobia (que está detrás de la obsesión con el igualitarismo). Todo en la cultura europea está dirigido a impedir que prospere el hombre fuerte, aquél que el débil presiente peligroso. La educación, por ejemplo, ya es el primer mecanismo para arruinar toda excepción y fomentar la homogeneización. El malo es el individuo libre, impredecible. La moral también colabora en este sentido alabando la sumisión, la humildad, las normas universales... La política lo hace con su igualitarismo (jincluso las feministas que intentan abolir la diferencia de sexos se equivocan al perseguir la igualdad, igualación con el hombre europeo enfermo!). 2) El deseo de bienestar o confort que ha llevado a dominar la naturaleza haciendo de ella algo manejable y calculable, pero al precio de hacer del hombre también un animal regular y predecible. El europeo moderno no es más libre aunque él lo crea. La moral ha recubierto de un halo de venerabilidad el trabajo, la producción, la esclavitud, mientras ha demonizado el ocio y el descanso. El trabajo, además de debilitar, produce individuos intercambiables. En la cultura aristocrática de Grecia el trabajo era lo malo y el ocio lo honorable.

La nivelación del hombre europeo se muestra pues como un proceso irreversible, una enfermedad sin cura que curiosamente parece escapar a la voluntad de los individuos. Nietzsche, optimistamente (casi hegeliano-marxistamente, llega a decir que dicho proceso debería ser incluso acelerado de manera voluntaria) trata de ver en ello la condición necesaria para la transvaloración, para que sea posible el surgimiento de una élite de aristócratas ociosos y creadores que no ejercerían su dominio en la esfera política sino en la más espiritual de la filosofía y el arte, ejerciendo o irradiando su influencia sobre los demás por la ejemplaridad y el carisma. Puesto que Nietzsche concebía el mundo como un inmenso "monstruo de fuerza", como una cantidad constante de energía-fuerza que 
sólo cambia de formas o configuración pero que ni se crea ni se destruye, el actual estado de debilidad que supone el nihilismo tiene que generar un excedente acumulado de fuerzas del que derive una elevación del tipo hombre, la aparición de esa casta de individuos afirmativos y creadores.

Desde el punto de vista genealógico y de la concepción del mundo como voluntad de poder, la historia de la cultura europea será la historia del triunfo de una voluntad de poder y de cómo ha conseguido imponer sus interpretaciones y valores. Es la historia de la selección, cría y domesticación de una especie de hombre a través de la imposición y generalización de sus condiciones de vida como valores (haciendo que los incorpore e introyecte como instintos suyos). Esa tarea domesticadora, puesto que nace de fuerzas reactivas, se ha realizado de forma violenta (mientras la fuerza se ejercita de modo espontáneo, creativo y activo, la violencia es siempre reactiva, es la descarga de un instinto hecha por un organismo débil que no es capaz de dominarlo o sublimarlo, incapacidad en definitiva para asimilar o digerir la realidad que es lo mismo que no poder dominar el caos que se es). La culturización europea del hombre ha sido su desnaturalización, se le ha convertido en un animal doméstico, débil, gregario, enfermo. El adiestramiento del animal se obtiene debilitándolo. El hombre moralizado no es mejor, es débil, desfigurado, pero eso sí, menos peligroso. Se ha conseguido domesticarlo y debilitarlo con la sibilina táctica de asociar y envenenar los instintos más vitales con la mala conciencia. Los individuos han introyectado mediante medios violentos, cuyo catálogo ocuparía volúmenes con atroces horrores, esos afectos deprimentes que desde entonces acompañan a los instintos poderosos, especialmente el sexo: "ino es espantoso convertir sensaciones necesarias y regulares en fuente de miseria interior [...] ¡ hermanar la fecundación humana con la mala conciencia!" ${ }^{4}$. Toda esta estrategia delata una voluntad débil, que pretende vengarse de los fuertes generalizando la enfermedad y el contagio. Lo que el débil no podía soportar lo ha convertido en insoportable en sí, por ejemplo el sufrimiento. De ahí que haya ensalzado la compasión, que sólo deprime y pone enfermo. El fuerte no se obsesiona con el dolor sino que lo asume como constitutivo del mundo, sabe que el placer aparece asociado a la superación de una fuerza que se le opone. Mediante la venganza es como una voluntad enferma siente placer y aumento de poder. En todo este proceso de doma del hombre juega un papel importante el olvido: el hombre incorpora esos rasgos al socializarse pero ya no

\footnotetext{
4 Aurara, aforismo 76.
} 
recuerda las fuerzas que han fijado en él esos valores. Las verdades son ficciones de las que hemos olvidado el carácter ficticio. Aquí el método genealógico podría compararse con una arqueología y Nietzsche, antes que Freud, habría concebido la cultura como enfermedad, el malestar en la cultura.

Ya ha aparecido más arriba la transvaloración y es que Nietzsche no era un mero teórico que se conformase con emitir el diagnóstico de la cultura europea, el análisis de la misma era el medio para un fin práctico, el de sustituirla por otra cultura no nihilista, afirmativa (he aquí otro paralelismo con Marx). El hombre es el animal aún no fijado y la herramienta con la que se le moldea, se le culturiza, es la tabla de valores. Junto a la actual moral nihilista caben otras, aunque ella se proclame la Moral, única y con mayúscula. Por eso Nietzsche quiere hacer el experimento de un hombre nuevo mediante un cambio en la tabla de valores, una transvaloración. Esta nueva moral no es una utopía porque la historia muestra que ese hombre ha existido en otros tiempos y lugares, bien fuera por azar, por un acúmulo de fuerzas u otras causas. Ejemplos tenemos en los griegos y alguna figura del Renacimiento como César Borgia. Nietzsche no es un utopista que proponga una revolución ni el uso de la violencia (¡cuantas malas interpretaciones ha habido aquí!), la cual es patrimonio de la reactividad. No sería útil tampoco una campaña informativa de concienciación que apelase a la razón de los hombres, pues ésta es siempre un estrato superficial y secundario en ellos, es su cuerpo donde quedan grabadas las primigenias valoraciones vitales en forma de instintos. Estos hombres están enfermos y a una enfermedad no se la combate con argumentos, no se puede refutar una moral que representa las condiciones de existencia de los individuos, se puede refutar una opinión pero eso no cambia los motivos que la hacen necesaria. Siendo pues el cuerpo al que hay que dirigir la acción transformadora, habrá que crear una cultura nueva que suponga una reorganización instintual del hombre. Y esa cultura nueva sólo la pueden crear una casta de hombres nuevos que creen unos valores nuevos y los porten mientras coexisten con la masa de hombres nihilistas que caminan hacia su extinción. Esto es posible porque los instintos no son algo innato, dado, sino que se moldean. Toda aquella serenidad de la cultura griega, de su arte, de su ciencia, de su política, suponían una gran fuerza para dominar una multitud de impresiones y reducirlas a una forma. Eso no le fue dado al hombre griego como un don natural, sino que lo tuvo que conquistar sometiéndose a una larga y rigurosa tarea de autosuperación. El hombre griego y su cultura son el ejemplo para los hombres que quieran experimentar en sí mismos la transvaloración, moldearse 
según unos valores distintos, afirmativos y sin tener mala conciencia por ello, unos hombres que estén dispuestos a crear una cultura superior y afirmativa que permitirá a su vez la elevación del tipo humano (ya que toda cultura es selección de un tipo de hombre) gracias a la acumulación de fuerza junto con la capacidad para dominarla. A fin de cuentas será esta una cultura que coincida con la dinámica de la vida como voluntad de poder. Esta cultura debe potenciar las pasiones, no extirparlas, así como su jerarquización, es decir, que haya alguna que domine a las otras ya que es la anarquía instintiva característica del individuo incapaz de dominarse la que debilita y disipa la fuerza. Una correcta educación se dirigirá a los instintos (igual que un guerrero se entrena para hacer sus movimientos automáticos, instintivos) que son las instancias primeras del comportamiento y no se justifican racionalmente (el tipo de hombre hiperracional, abstracto, socrático, el europeo de hoy está desnaturalizado, no posee instintos reguladores propios). Hay que procurar una apertura máxima a la diversidad pasional y luchar por integrarla y dominarla, eso es lo que hacía el griego que admitía todas sus pasiones sin negar ninguna (incluso instituía fiestas en honor de las más perversas). El griego en lugar de descargar violentamente sus instintos, los espiritualizaba o sublimaba para utilizarlos en una dirección creativa. $\mathrm{El}$ artista nunca niega sus impulsos ni los descarga violentamente, él los domina con ayuda de de otros impulsos y los desvía hacia un uso espiritual. Por tanto, si los instintos ya no son la naturaleza "en sí» del hombre sino algo que es configurado, entonces no puede haber ninguna supuesta vuelta a lo natural. A este hombre nuevo que debe estar lleno de pasiones contradictorias a las que consiga dominar, Nietzsche le adjudicó varios nombres de los cuales el de "Übermensch" o superhombre parece ser el más idóneo. Lo cierto es que no se ha sabido muy bien con quien identificar la figura de este superhombre, Sánchez Meca cree que se trata de la figura del filósofo. Lo que sí está claro es lo que caracteriza a este hombre, el pathos de la distancia, la soledad pero no como renuncia a la vida, la creatividad, la afirmación, el desinterés por los débiles del rebaño de quien no se siente médico ni redentor y por los que no siente ninguna compasión. El superhombre permanece apartado en su esfera propia, con su moral que no pretende predicar a los demás, no quiere tampoco dominar ni gobernar al rebaño pues esta tarea política no deja de ser para él una esclavitud. A pesar de estas afirmaciones hay otras en las que Nietzsche parece admitir que el superhombre necesita al hombre de rebaño, su rivalidad, para distanciarse de él. Ello parece suponer una contradicción que en realidad sólo es imputable al intérprete ya que Nietzsche nunca persiguió la coherencia lógica, su escritura perseguía un fin prác- 
tico y no la mera transmisión de conocimientos, pretendía producir un efecto, ayudar a transformar el mundo y la visión de éste. Para Nietzsche la exposición lógico-conceptual uniformiza y elimina los matices cumpliendo simplemente con el objetivo de cubrir la necesidad de comunicación. Nietzsche busca seducir y nos equivocaremos si acudimos a él pertrechados con las tradicionales categorías lógicas (tampoco nadie intenta entender una obra de arte con tales herramientas, sino más bien sentirla), una refutación lógica no supone una prueba en su contra ya que no elimina sus efectos (igual que sucedía con su archienemiga la moral nihilista) y por eso no le preocupaba incurrir a veces en contradicciones lógicas. A él le interesaba más el arte que la verdad, el efecto sobre la voluntad que la coherencia lógica, y en ese sentido utilizaba la multiplicación de las perspectivas en vez de un discurso lógico que no podía dar cuenta del carácter trágico de la existencia, de la realidad como devenir, como voluntad de poder.

Por último Sánchez Meca examina lo que la idea del eterno retorno pueda significar según lo que hasta aquí se ha dicho. Su postura es muy clara. Es un error considerar esta "teoria" en sentido físico o metafísico, como si representara la constitución real del universo. El eterno retorno tiene un carácter eminentemente práctico dentro del proyecto nietzscheano de transformar la cultura europea, de hecho Nietzsche nunca le llamó "teoría", sino "doctrina", "profecía", "anuncio". Así como la moral nihilista se sirvió eficazmente de la religión cristiana, la nueva moral de señores utilizará el pensamiento abismal del eterno retorno que no constituye un enunciado dirigido al entendimiento, sino una prueba para la voluntad, la prueba en que propiamente consistiría todo su experimento ya que al suponer la más alta afirmación de la vida que quepa imaginar permite seleccionar al tipo del superhombre (por eso el eterno retorno pertenece a la esfera de la cultura.). El débil no puede soportar está idea del eterno retorno, la idea de esta vida, que para él es una carga, retornando siempre igual, idéntica a sí misma. Para el hombre fuerte y sano la idea del eterno retorno supone sintetizar la diversidad del tiempo (pasado, presente y futuro) bajo esta forma y tener así cada instante por eterno. La idea del eterno retorno es algo cultural, algo que debe ser introyectado como un instinto, como una condición de la vida ascendente.

\section{3. " parte. "Dioniso ambiguo o Nietzsche en discusión"}

Sánchez Meca no comparte la interpretación habermasiana de Nietzsche que hace de éste un romántico que pretende salvar los desgarramientos de la moder- 
nidad mediante una vuelta a lo natural, a la Grecia arcaica. Según esta visión Nietzsche desarrolla el proyecto romántico de crear una nueva mitología que es lo que le falta al hombre moderno nihilista, es decir, que la terapia consistiría en una remitologización a través del arte como experiencia mística de fusión con lo dionisiaco. Jürgen Habermas se equivoca al tomar la parte por el todo, al quedarse con una concepción que a lo sumo sólo sostuvo el joven Nietzsche, hecho que le impide dar cuenta de la evolución de su pensamiento, del distinto concepto que tenía del arte y de lo dionisiaco el Nietzsche maduro, como ha tratado de demostrar el presente libro (y por eso mismo no puede Habermas explicar tampoco como algo fudamental la ruptura de la amistad con Wagner, sino que dentro de su interpretación dicha ruptura queda necesariamente reducida al rango de mera anécdota biográfica).

En cuanto a Martin Heidegger, el esquema apriorístico que aplica a la hora de interpretar a todo filósofo y que consiste en hacer de la historia (también la del pensamiento) el desenvolvimiento de la metafísica, no puede ser el adecuado para entender a Nietzsche, pensador que, según él, representaría la culminación de la metafísica, la preponderancia absoluta del ente (que sería la voluntad de poder) frente al olvido del ser. A tal fin hace confluir Heidegger los conceptos básicos de la filosofía nietzscheana (nihilismo, eterno retorno, superhombre y justicia) como distintas formas de expresar el ente (la voluntad de poder). Es este un punto de vista original pero no muy esclarecedor. Parece también excesivamente unilateral la interpretación heideggeriana del eterno retorno como acto de decisión existencial tomado en el interior del individuo, así como que esta idea junto con la de voluntad de poder representen la dinámica propia de la técnica que se autoalimenta y que sería la tarea final de la metafísica dirigida a organizar y dominar el ente.

En último lugar, la interpretación de Gilles Deleuze parece ser la más cercana a la del propio Sánchez Meca. Al pensador francés le atrajo epecialmente la concepción nietzscheana de la filosofía como crítica, hasta el punto de ver en Nietzsche el auténtico viraje crítico de la modernidad contra la filosofía clásica, y no en Kant, quien habría traicionado la crítica en el momento mismo de emprenderla por seguir asumiendo el conocimiento de lo verdadero como problema fundamental de la filosofía. En este aspecto el concepto de voluntad de poder debe ser un nuevo inicio para el pensamiento que acabe con la vieja metafísica. La vieja razón no permite pensar la diferencia, mientras que la filosofía de Nietzsche sí es un pensamiento de lo múltiple y la diferencia. 
Finalmente uno se alegra con el Nietzsche que nos trae este libro, aunque sea el Nietzsche duro, el que no escribía para todos, el que nos dice que somos enfermos. En este sentido es el libro de Sánchez Meca también un libro trágico pues cada paso que se da en la comprensión de ese pensamiento forjado a seis mil pies por encima de todo lo humano, donde soplan vientos que no cualquiera puede respirar, supone un ejercicio de fortaleza, de asimilar cosas nada fáciles de masticar y tragar. 
SABIDURfAS ORIENTALES DE LA ANTIGÜEDAD, Alianza Ensayo, 2004, $408 \mathrm{pp}$.

Iñaki Preciado Idoeta Sinólogo y tibetólogo

Sabidurias Orientales de la Antigüedad es una obra que viene a colmar una importante laguna en el ámbito del orientalismo en nuestro país. Libros sobre temas relacionados con este campo no faltan, por supuesto, pero en todos los casos adolecen de algún "defecto", bien sea su limitación en el espacio, bien sea su insuficiente nivel en cuanto a rigor académico. Y ése es precisamente el mérito y el servicio del libro escrito por María Teresa Román López, pues a su erudición y rigor, une la visión panorámica de las diferentes corrientes de pensamiento que se desarrollaron en el curso de varios milenios por el inmenso Oriente. Un Oriente, tan próximo como lejano, o si se quiere tan próximo pese a la lejanía; y esto último pese a la ignorancia, cuando no menosprecio, de que ha sido, y sigue siendo, objeto por parte de no pocos prohombres de nuestro insolente $y$ engreído mundo occidental. Para ellos, en el inmenso saco de la "sinrazón" se debería meter la mayor parte de esas milenarias sabidurías, de las que solo contemplan el denominador común de un pretendido irracionalismo, sin pararse a considerar la riqueza de contenidos, y la diversidad de vías que se han seguido en las diferentes (incluso muy diferentes) culturas para aproximarse al conocimiento de la auténtica realidad (o irrealidad). Pues bien, el libro de María Teresa Román nos presenta ese panorama del mosaico oriental, desde Egipto y Mesopotamia hasta la remota China, pasando por las sabidurías centroasiáticas y del subcontinente indio. Sobre todas ellas se ha escrito en nuestro país, y mucho y bien en algunos casos (Egipto, Hinduismo, Budismo, ...), pero pocas son las obras en las que el conjunto incluye estudios serios y bien documentados sobre Mesopotamia y sobre las creencias de los antiguos pueblos que habitaron el territorio iranio. Y sobre todo, es de destacar y de agradecer la valiosa información que nos proporcionan los dos primeros capítulos, donde se desarrolla un estudio comparativo entre Oriente y Occidente, y una aproximación global a esas sabidurías orientales (junto con una muy interesante historia del orientalismo en Occidente), en la que se nos descorre el velo y se ilumina ese mundo tan fascinante para una mente abierta y libre de prejuicios. 
En el libro ese mundo se nos muestra en toda su riqueza, desde las profundidades de sus doctrinas metafísicas, hasta la desbordada imaginación de sus mitos y el colorido misterio de sus rituales. A través de sus exposiciones y descripciones, vamos comprendiendo cómo nuestros antepasados se enfrentaron a sus miedos existenciales y cuáles fueron sus respuestas y mecanismos para superarlos. Es por tanto un libro de un gran valor no sólo para quien desee acercarse al conocimiento de esas antiguas sabidurías, sino también para el que sienta interés por viajar al universo mental de nuestros ancestros, al que tanto debe, y sin el que no se puede explicar ni entender, el nuestro propio.

La estructura del libro no se atiene a un orden diacrónico, sino estrictamente espacial. Recorremos las diferentes sabidurías como si viajáramos en una antigua caravana que partiendo de Egipto nos condujera, rumbo al Este: Mesopotamia e Irán, primero, y luego a la India. Aquí nos detenemos por un tiempo. Es como si en el subcontinente se condensaran todos estos saberes del mundo asiático. A él están consagrados dos extensos capítulos (hinduismo y budismo), y bien puede decirse que es la parte mejor acabada del libro. La meta final, China, y sus corrientes fundamentales de pensamiento (confucianismo y taoísmo, principalmente), culminan el largo viaje.

Por último, hay dos puntos que cumple señalar. Por un lado, la abundante y valiosa bibliografía que se añade al final de cada capítulo; y por otro, la presentación, bajo el epígrafe "El legado de ....», del marco cultural en el que se inscribe cada una de las sabidurías estudiadas, y en la que en algunos casos se incluye una introducción a las correspondientes lengua y literatura.

En resumen podemos decir que el libro de María Teresa Román marca un hito en el campo del orientalismo español, y esperamos que la autora prosiga en su meritoria labor de dar a conocer entre nosotros otras sabidurías menores del mundo asiático, aún escasamente conocidas. 